\title{
The Precipitation of Primary Carbides in Alloy 718
}

\author{
A. Mitchell, A.J. Schmalz, C. Schvezov and S.L. Cockcroft \\ Department of Metals \& Materials Engineering \\ University of British Columbia \\ Vancouver, B.C., Canada \\ V6T $1 \mathrm{Z4}$
}

\begin{abstract}
The precipitation of primary MC carbides in alloy 718 has been studied using the techniques of directional solidification with and without quenching. The precipitation reaction;

$$
[\mathrm{Nb}]+[\mathrm{C}]=\mathrm{NbC}(\mathrm{s})
$$

is found to follow normal thermodynamic relationships in alloys which have an amount of nitrogen well in excess of the saturation solubility of TiN at the carbide precipitation temperature. For alloys containing only small amounts of nitrogen ( $\mathrm{N}<14 \mathrm{ppm}$ ), made by electron beam remelting, the carbide precipitation is delayed to a lower temperature due to a lack of TiN nucleating sites. As a result we find that in these alloys both the as-cast structure and the response to homogenisation are significantly changed from those of the conventional alloy compositions. The implications of this finding in relation to potential alloy composition modifications in order to improve carbide distributions are discussed.
\end{abstract}

\section{Introduction}

There have been many studies of the as-cast structure of IN718, with various compositions $(1-3)$. The studies have defined the basic solidification sequence, which may be characterised as one in which the first solid to precipitate is a solid solution gamma $(\gamma)$, followed by the formation of primary carbides $(\mathrm{Nb}, \mathrm{Ti}) \mathrm{C}$ and subsequently either a single eutectic(2) or a series of divorced eutectics (3) consisting of $\mathrm{NbC}, \gamma$ and a Laves phase of variable composition based around;

\section{(wt\%); Ni35 Nb31 Fe13 Cr13 Mo7 Ti1 Sil}

depending on the freezing conditions and on the precise alloy chemistry. Other phases have been reported; inclusion particles of $\mathrm{Al}_{2} \mathrm{O}_{3}, \mathrm{MgO}$ or TiN, primary delta phase ( $\delta$ ), (basically $\mathrm{Ni}_{3} \mathrm{Nb}$ ) and also the similar phase of gamma prime $\left(\gamma^{\prime}\right)(4)$. Since most of these phases are extremely stable against solid-state heat treatment, the solidification structure becomes very important in determining the alloy's subsequent properties. In addition, the phase precipitation is connected with the solidification segregation, which in turn determines the local solvus temperatures of both $\delta$ and $\gamma^{\prime}$, and therefore also the property dispersion of the structure. In this work, we have concentrated on a particular aspect of the solidification behaviour of IN718; the precipitation of the primary carbide and the role of nitride inclusions.

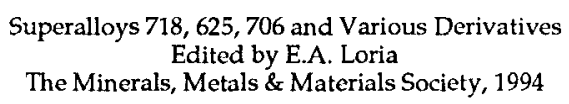


The primary carbides are not taken into solution at temperatures below the eutectic and their size distribution cannot be significantly altered in normal heat treatment procedures, although some evidence of Ostwald ripening has been reported at temperatures close to the eutectic range. This effect has been used to alter the metallographic appearance of the carbide distribution in regard to carbide number, but probably with little effect on properties. In superclean IN718, the primary failure mode in LCF is crack initiation at carbide clusters (5), and so it is of some importance to control the carbide precipitation process.

The conditions for the precipitation of titanium nitride inclusions have been defined in the literature (6), and we find that in most commercial versions of the alloy, the precipitation reaction starts in the fully-liquid state. The liquid therefore contains a distribution of TiN particles at temperatures above the liquidus and prior to the start of solidification. These particles are quite small $(1-10 \mu \mathrm{m})$, and often have themselves nucleated on prior-existing oxide inclusions (13). The nitrides act as nucleating sites for the primary carbide precipitation and the carbides are frequently found with nitride cores, leading to the common term "carbonitrides" for their description. Further nitride precipitation takes place during freezing, because of the temperature dependence of the solubility product, until essentially all of the nitride has been deposited at the eutectic start temperature (6). Carbide precipitation takes place over a range of temperature which depends on the composition and freezing rate (7). Since there are no reports of $\mathrm{M}_{23} \mathrm{C}_{6}$ carbides in the heat-treated IN718 structures, it would be reasonable to infer that almost all of the carbon in the alloy is present in the solid as primary $\mathrm{MC}$ carbide, precipitated either prior to the eutectic start or during the eutectic reactions themselves.

The size distribution of the primary carbides is related to the freezing rate of the alloy. It has been found (7) that the local solidification time of the alloy can be monitored in a sensitive manner by the average size of the largest carbide particles, which can be interpreted as indicating that the larger carbides are those which precipitate in the temperature range well above the eutectic start. Since these carbides are also those which have the greatest chance to agglomerate by liquid movement, they are of prime interest in relating the freezing conditions to mechanical properties.

\section{Experimental}

The alloy compositions used are shown in Table 1 and were provided by the courtesy of Inco Alloys International Inc., Cannon-Muskegon Corp. and Deloro Stellite Ltd. All of these alloys were melted by vacuum induction and supplied in the ingot form. One of the alloys was processed by clcctron-bcam mclting at UBC to further reduce the content of nitrogen and to remove the remaining small content of oxide inclusions. The alloys were sectioned mechanically into sizes suitable for the experimental programme. The general methods chosen for the study were those of directional solidification/quench (DSQ) and directional solidification under conditions of gradient and temperature such that the solidification mode changed from columnar-dendritic to equiaxial (CET). In both cases the equipment was of conventional design with DS parameters chosen to approximate the conditions found in commercial vacuum-arc remelting of this alloy. The equipment is shown schematically in Figures $1 \& 2$.

In the DSQ samples, the temperature gradient was held constant at $16^{\circ} \mathrm{C} / \mathrm{mm}$ and the solidification rate was $0.14 \mathrm{~mm} / \mathrm{s}$. The CET ingots were frozen in a range of rates from 0.05 $5.0 \mathrm{~mm} / \mathrm{s}$, and gradients from $5.0-0.05^{\circ} \mathrm{C} / \mathrm{mm}$ respectively. The samples were sectioned mechanically for examination by optical and electron metallography, and also by DTA. 


\section{$\underline{\text { Results }}$}

\section{Alloys prepared by VIM}

The most notable feature observed in all conventionally melted samples is the rapid increase in the number of carbide particles as a function of distance into the freezing zone. When assessed by the method of Wadier et al (7), i.e. number of carbide particles/field at $100 \mathrm{x}$, the count increases from 5-10 to 120 - 180 over a relatively short distance. The carbide size distributions in the present alloy samples were also found to be in general agreement with the ranges reported by Wadier for the appropriate local solidification times. At the end of solidification, approximately $80 \%$ of the carbide particles were found to be inside the dendrite structure with the remaining $20 \%$ in the interdendritic regions. Figure 3 illustrates this in the final structure of a typical sample, 86A, in which the intradendrtic, interdendritic, and carbonitrides are identified.

The precipitation-start temperature varies with the sample composition, as would be anticipated from the chemical equilibrium involved and will be discussed below.

The data on carbide counts for the DSQ experiments are presented in Figures 4 - 7, and since they represent solidification in a known and fixed temperature gradient, it is possible to convert distance into temperature, using the reported liquidus of the alloys (8). There is an element of uncertainty in this method, due to the uncertain undercooling at the liquidus, but the error is thought to be small in the DSQ conditions chosen. It should noted here that only data for interdendritic carbides was determined for sample 64, and for sample 89 (see Table 1) with $0.007 \mathrm{wt} \%$ carbon, no carbides were detected.

The data shows clearly that there is no carbide formation in these compositions at temperatures above the liquidus. However, titanium nitride can be precipitated in the liquid when the nitrogen content exceeds approximately 40ppm (6), and in some of the alloys this effect could be seen. It has also been reported (9) that the carbide dissolves very quickly in the alloy at temperatures above the liquidus and hence no carbides in the DSQ or CET samples were relics of original carbides in the VIM starting alloy. Although the carbide (whether it is pure $\mathrm{NbC}$ or a mixed $\mathrm{Nb}-\mathrm{Ti}, \mathrm{C}$ ) has a density lower than that of the bulk liquid IN718, we found no evidence of carbide flotation from the solidifying region, or any evidence of carbide particle pushing by the freezing solid although both of these were specifically sought in the examinations. (It may be noted parenthetically that no evidence of these two effects was found also in the case of titanium nitride particles). The final carbide distribution shows $80 \%$ within the dendrite envelope, although these carbides must have been precipitated in the liquid in the region of the advancing dendrite front. This finding confirms the postulate that the particles are not pushed by the freezing interface but instead are enveloped by it. This is evidenced by the peaking of the interdendritic counts in Figures 4-7 which diminishes as carbide envelopment and solidification is completed.

The sharp increase in particle number occurs at $1276^{\circ} \mathrm{C}$ in samples $61 \mathrm{~A}$ and $65 \mathrm{~B}$; and at $1245^{\circ} \mathrm{C}$ in sample 86 . The onset of carbide precipitation has been quoted as $1257^{\circ} \mathrm{C}$ by Cieslak (1)and $1250^{\circ} \mathrm{C}$ by Bouse (8) using DTA in a similar composition to that used for $61 \mathrm{~A}$ and $65 \mathrm{~B}$. In the case of the present range of alloys, the carbide precipitation start temperature appears to be between $1250-55^{\circ} \mathrm{C}$, as shown in Figure 8 .

The carbide size range observed is also in good agreement with published data for the range of freezing conditions used. In all of the samples, particles which contained a nitride core 
were found to form a larger size fraction than the pure carbide particles probably indicating that the particles nucleated by nitrides are the first to form and so have a longer time to grow during the freezing process. This effect appears to be more pronounced than the influence of carbide-start temperature, since there was no detectable difference in carbide size distribution between the various compositions which precipitated carbides. At much longer local solidification times than those used in the present study, it might be possible to detect a difference due to the composition influence on the carbide-start temperature.

The driving force for carbide precipitation is the segregation of carbon and niobium as the alloy freezes. This segregation has been reported in the literature (10). We find (Figure 9) that the niobium content varies from a low of $2 \mathrm{wt} \%$ in the center of the dendrite core to 22 $\mathrm{wt} \%$ in the last liquid to freeze, in agreement with the literature values. Applying the Scheil analysis to the results of Figure 9 reproduces the observed concentration profile when using a segregation coefficient of 0.5 , in good agrccment with the value used by Bouse (8). The segregation coefficient for carbon can be obtained indirectly by using a mass balance approach, as shown in Appendix 1, where we see that a satisfactory closure is obtained when the carbon segregation coefficient is assumed to be 0.1 .

In all cases, the fraction of carbon present as massive carbides is small, less than $20 \%$ of the total carbon. The fraction of carbon in the eutectic region varies from $66-77 \%$, with a total volume fraction of eutectic of $7-9 \%$, in agreement with the literature (11). The carbon balance is of interest also in that it shows (Appendix 1) that essentially all of the carbon present must be in the form of $\mathrm{MC}$ carbide using the literature values for the volume fraction of carbide determined by chemical extraction (approximately $0.35 \mathrm{vol} \%$ ) (11), which accounts for the fact that IN718 does not show any low temperature precipitation of other carbides e.g. $\mathrm{Cr}_{23} \mathrm{C}_{6}$. It is also worth noting that the niobium equivalent of this carbon is quite small (approximately $0.35 \mathrm{wt} \%$ ) in comparison with the total niobium content, but could represent a critical difference in concentrations in compositions close to the eutectic Laves phase precipitation point, e.g. in the case decribed below. It should be taken into account in any changes in the formulation of the alloy which concern changes in carbon content. The system has a solid fraction of approximately 0.5 at the carbide-start temperature, which can be used to make an estimate of the range of equilibrium values for the solubility product of $\mathrm{NbC}$ in this alloy. In all cases, the carbon concentration in the liquid when carbides start to form is $0.25 \mathrm{wt} \%$, and the niobium concentration is $10.5 \mathrm{wt} \%$ the product is;

$$
[\mathrm{wt} \% \mathrm{Nb}] \times[\mathrm{wt} \% \mathrm{C}]=2.63
$$

It is clear that the niobium and carbon segregation in the low carbon sample (89) will not reach this value and hence we do not observe primary carbides in this alloy. Using the published value for the free energy of formation of $\mathrm{NbC} \mathrm{(12),} \mathrm{we} \mathrm{obtain} \mathrm{the} \mathrm{following;}$

$$
1260^{\circ} \mathrm{C} ; \quad\left[\mathrm{a}_{\mathrm{Nb}}\right] \times\left[\mathrm{a}_{\mathrm{C}}\right]=0.000055
$$

for the solubility product expressed in Raoultian activities. Experimentally, at the point of carbide precipitation;

$$
\left[\mathrm{N}_{\mathrm{Nb}}\right] \times\left[\mathrm{N}_{\mathrm{C}}\right]=0.0067
$$

Comparison of the values in (2) \& (3) indicates a strong negative deviation from ideality, as would be expected in a concentrated solution in the process of precipitating a stable compound. 


\section{Electron-Beam Melted Alloy}

As will be seen from Table 1, the nitrogen contents of the alloys used vary considerably. The highest quality commercial alloy contains approximately $16 \mathrm{ppm} \mathrm{N}$, whilst more conventional material can contain up to $100 \mathrm{ppm}$ N. Since this range encompasses the value required to satisfy the solubility product at the liquidus $(40 \mathrm{ppm} \mathrm{N})$, we would expect to see some influence of nitrogen content on the precipitation reactions during solidification. Since both nitrogen and titanium segregate during solidification, the nitrogen content at the saturation solubility is a strong function of temperature. It has been estimated (13) that the nitrogen equilibrium content in solution at the eutectic is approximately $5 \mathrm{ppm}$. We may expect, therefore, three regimes of influence of nitrogen on the carbide precipitation process; (i) solid TiN particles present at all stages of solidification $(\mathrm{N}>40 \mathrm{ppm})$

(ii) TiN precipitated at and below the carbide-start temperature $(\mathrm{N}=15 \mathrm{ppm})$

(iii) TiN not precipitated during solidification $(\mathrm{N}<5 \mathrm{ppm})$.

(The above assumes that there is no mutual solubility between TiN and $\mathrm{NbC}$ which would reduce the activity of the TiN component of the reaction).

All of the VIM alloys used contain nitrogen at levels above the value (ii) above, and it was not possible to identify any different effects of TiN on carbides between the levels of (i) and (ii). The technique of EB melting used was one in which the alloy was not significantly superheated above the liquidus, and where the melting rate was very low in order to encourage desorption of nitrogen. The starting alloy was the VIM alloy lowest in nitrogen $(16 \mathrm{ppm})$. Chemical analysis following the EB melt showed a small loss of chromium $(-0.15$ wt $\%$ ), but no other composition change except for a reduction in the nitrogen content to the range $6-14 \mathrm{ppm}$. The EB alloy was processed by the CET technique and examined in the same way as the above systems.

Micro examination of the EB alloy shows that under the same freezing conditions, it shows much less primary carbide than does the "normal" alloy, and also has a eutectic structure which is different, (Fig 10). The carbide composition is the same as that in a non-EB alloy, as is the morphology, but in no case could a carbide with a nitride core be found; neither could any trace of TiN be found in the remaining structure. We conclude that the nitrogen level in the liquid at the eutectic is below that required for $\mathrm{TiN}$ precipitation and that the nitrogen is either precipitated as $\mathrm{TiN}$ in particles too small for the present detection methods, or it is contained in solid solution in the eutectic MC carbide. In view of the known solubility of nitrogen in MC carbides, the latter seems the more likely result. The influence of the nitride on carbide formation is an indication of the non-equilibrium nature of the precipitation reaction. The effect of nucleating agents on the carbide precipitation as opposed to grain-size modification has not been reported previously, although the non-equilibrium precipitation of MC carbides in high-speed steels has been recognised (14). In this case it would appear that the presence of TiN nuclei (or possibly also large oxide particles) are necessary for the precipitation reaction to take place at the temperatures indicated by DTA on conventionallymelted alloys. When we remove all potential nucleants, the carbide formation is delayed until the eutectic temperature. In addition, the eutectic reaction itself is altered because the liquid composition is no longer the same as in the previous case. Some support for this hypothesis can be gained from an examination of rapidly-frozen IN718, and also from IN718 with a very low carbon content. (15). In both of these cases, the primary carbide precipitation is delayed until the eutectic reactions start; also the eutectic structure is the same as that shown by the EB case in Fig 10 i.e. no blocky Laves phase, and a fine $\gamma+$ Laves eutectic structure. There are also literature reports of the presence of primary delta phase in very low nitrogen IN718, which could account for the "needle" structure shown in the EB alloy of Fig 10, and its 
formation has been explained by Radhakrishnan and Thompson (3). It would appear that the effect of EB processing to give very low nitrogen and oxide contents produces structures at long local solidification times that resemble those found at very short times in more conventional alloys.

The EB alloy structure also reacts quite differently to high temperature homogenisation heattreatment. After a one hour exposure at a temperature normally used to decompose the Laves phase in IN718, we can see a marked difference in alloy structure from the conventional material, as shown in Fig 11, in which the EB structure is clearly more uniform, free from retained Laves phase and contains a finer primary carbide distribution. The conventional alloy required an eight hour treatment at the same temperature to produce the same Laves-free structure, probably due to the longer diffusion distances needed to decompose the blocky morphology, in contrast to the ready dissolution of $\delta$ in the EB refined alloy at this temperature.

The findings call into question the basis for composition formulation in IN718, and also possibly in the entire range of $\mathrm{MC}$-containing superalloys. It is evident that we must take into account not only the carbide precipitation reaction itself in determining the carbide distribution, but also the nitrogen content.

\section{$\underline{\text { Conclusions }}$}

We conclude that the precipitation of primary carbides in IN718 is a non-equilibrium process which can be substantially influenced not only by the base alloy composition, but also by the presence or absence of nucleating particles, particularly titanium nitride.

The segregation parameters necessary for the precipitation have been defined, leading to an estimate of the composition changes necessary to prevent primary carbide formation before eutectic solidification. The absence of primary carbide precipitation caused by a lack of nucleating agents alters the eutectic compositions and also their response to heat treatment.

It is likely that the mechanisms discussed in this work also apply to the precipitation of primary carbides in other superalloy compositions, which suggests that the nitrogen content of these alloys should be taken into account when analysing or predicting the as-cast microstructure, or the response of the as-cast structure to heat-treatment.

\section{Acknowledgements}

The authors gratefully acknowlcdge the support of the Nickel Development Institute and the Natural Sciences and Engineering Research Council of Canada during the course of this study. They are also grateful to Inco Alloys International Incorporated, Special Metals Corporation, Deloro Stellite Limited and the Cannon-Muskegon Corporation for supply of the alloys used in the study and for analyses of the superalloy samples: and to L. Frederick and

C. Edie for their assistance.

\section{References}

1. M.J.Ceislak, G.A.Knorovsky, T.J.Headley and A.D.Romig, Jr.; "The Solidification Metallurgy of Alloy 718 and Other Nb-containing Superalloys", "Superalloy 718" ed E.A.Loria, publ. TMS-AIME, Warrendale, PA $1989,59-68$.

2. G.A.Knorovsky, M.J.Ceislak, T.J.Headley, A.D.Romig, Jr. and W.F.Hammetter;" Inconel 718; A Solidification Diagram"Metall. Trans. A, 20A (1989), 2147 - 2156. 
3. B. Rhadakrishnan and R.G.Thompson; "Solidification of the Nickel-based Superalloy 718; A Phase Diagram Approach"; Metall. Trans. A, 20A (1989),2866 - 2868.

4. X. Xie, Y. Zhang, Z. Xu, K. Ni, Y. Zhu, T. Zhang, Y. Tong, X. Ning, S. Zhang and J.F. Radavitch; "Effect of Oxygen, Nitrogren and Magnesium on Segregation, Solidification and Mechanical Properties in Alloy 718", "Superalloys 718 and 625", ed E.A.Loria, publ. TMS-AIME Warrendale PA, 1991, 241 - 251.

5. Personnel communication, Y Honnorat, 1992/ reported in"European Propulsion Forum 1993", Royal Aeronautical Soc., London UK.

6. A. Mitchell; "Recent Developments in Superalloy Melting Technology", "Synthesis, Processing and Modelling of Advanced Materials", eds. F.H.Froes and T. Khan, publ.Trans Tech Publications, USA, 1991, 177-187

7. A.S.Ballantyne, A. Mitchell and J. F. Wadier; "Prediction of Ingot Microstructure in VAR/ESR Alloy 718"; Proc. 6th International Conference on Vacuum Metallurgy, eds. G. K. Bhat and R. Schlatter, publ. American Vacuum Soc., New York, 1979, 599 - 623.

8. G. K. Bouse; "Application of a Modified Phase Diagram to the Production of Cast Alloy 718 Components"; "Superalloy 718" ed E.A.Loria, publ. TMS-AIME Warrendale PA., 1989, 69 - 79.

9. M Hilborn; unpublished research, Univ. of British Columbia, 1986.

10. U. Heubner, M. Kohler and B. Prinz; "Determination of the Solidification Behaviour of Some Selected Superalloys"; "Superalloys 1988", eds D.N.Duhl et al, publ. TMS-AIME Warrendale PA, 1988, 437 - 447.

11. J. M. Poole, Internal Report, INCO Alloys International, Huntington WVa, 1991.

12. W. L. Worrell and J. Chipman; "Carbide Equilibria at 1180 - 1370K", J. Phys. Chem. 68, (1964), 860 871.

13. S. L. Cockcroft, T. Degawa, A. Mitchell, D. W. Tripp and A. Schmalz; "Inclusion Precipitation in Superalloys", "Superalloys 1992" eds S.D.Antolovich et al, publ. TMS-AIME Warrendale PA, 1992, 577 - 589.

14 A. S. Ballantyne and A. Mitchell; "Prediction of Structure in VAR, ESR and PAR Ingots", "Soliditication and Casting of Metals", Metals Society, London UK, 1979, 363 - 371.

15. J.M.Moyer, "Extra-Low Carbon Alloy 718", "Proceedings of Superalloys 1984" eds. M. Gell et al, publ. TMS-AIME, Warrendale PA, 1984, 443 - 454.

16. K. O. Yu, J. A. Dominguc, H. Flanders; "Segregation in VAR and ESR Alloy 718", Proceedings Vacuum Metallurgy Conference, Pittsburgh, eds. G.K.Bhat and L. H. Lherbier, publ. American Vacuum Soc, New York, 1985, 1 - 8 .

Table 1. Various Compositions of Alloy 718 studied in the present work.

\begin{tabular}{|c|c|c|c|c|c|c|c|c|c|c|c|c|c|c|c|c|}
\hline \multirow{2}{*}{$\begin{array}{l}\text { N718 Variation } \\
\text { Sample Name }\end{array}$} & \multicolumn{16}{|c|}{ Composition } \\
\hline & $\mathrm{Ni}$ & $\mathrm{Cr}$ & $\mathrm{Fe}$ & $\mathrm{Nb}+\mathrm{Ta}$ & Mo & $\mathrm{Ti}$ & $\mathrm{Al}$ & c & N ppm & ppm & $\mathrm{Si}$ & $\mathrm{Mn}$ & $\mathrm{Mg}$ & B & $\mathrm{S}$ & $\mathrm{Cu}$ \\
\hline $61 \mathrm{~A}$ & 53.48 & 18.78 & 17.43 & 5.09 & 2.81 & 1.01 & 0.71 & 0.06 & 60 & -- & 0.42 & 0.054 & 0.0049 & 0.0043 & 0.003 & 0.0035 \\
\hline 64 & 53.28 & 18.4 & 17.27 & 5.62 & 2.84 & 0.02 & 0.76 & 0.02 & 60 & -. & 0.42 & 0.06 & 0.0071 & 0.0041 & 0.002 & 0.0025 \\
\hline $65 B$ & 53.58 & 18.32 & 17.53 & 5.67 & 2.82 & 1.02 & 0.71 & 0.05 & 60 & -- & 0.42 & 0.053 & 0.007 & 0.004 & 0.002 & 0.0025 \\
\hline 86 & 53.74 & 18.73 & 16.84 & 5.44 & 3.3 & 0.99 & 0.72 & 0.05 & 60 & -- & 0.089 & 0.054 & 0.0035 & 0.0038 & 0.001 & 0.004 \\
\hline 89 & 53.42 & 18.95 & 17.33 & 5.08 & 2.9 & 1.01 & 0.71 & 0.007 & 60 & - & 0.4 & 0.053 & 0.0070 & 0.0038 & 0.001 & 0.004 \\
\hline $\mathrm{CM}-718-\mathrm{SQ}$ & 52.8 & 19.5 & BAL. & 5 & 3.05 & 1.02 & 0.55 & 0.06 & 16 & 3 & $<0.02$ & 0.001 & -- & 0.004 & 19 ppm & 0.001 \\
\hline EBM-CM-718 & 53.54 & 18.59 & 18.13 & 4.922 & 3.1 & 0.98 & 0.62 & 0.056 & 11 & - & 0.014 & 0.001 & 0.001 & 0.0021 & 0.0016 & 0.015 \\
\hline
\end{tabular}




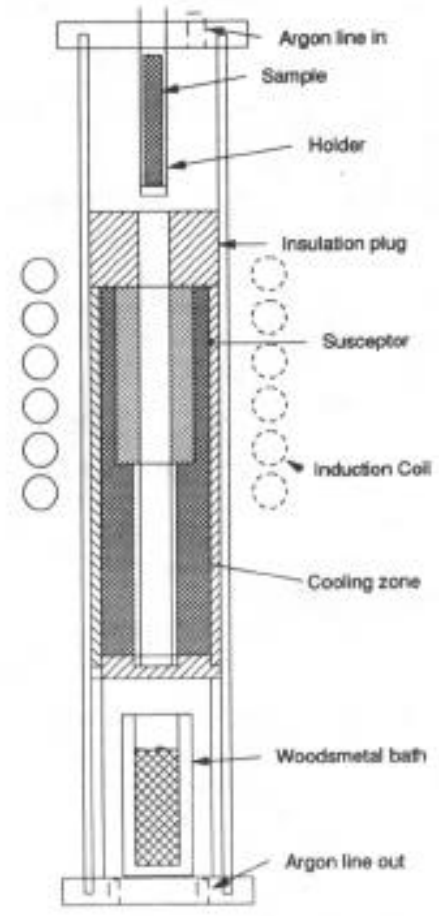

Figure 1. Schematic of Directional Solidification and Quench (DSQ) Furnace.
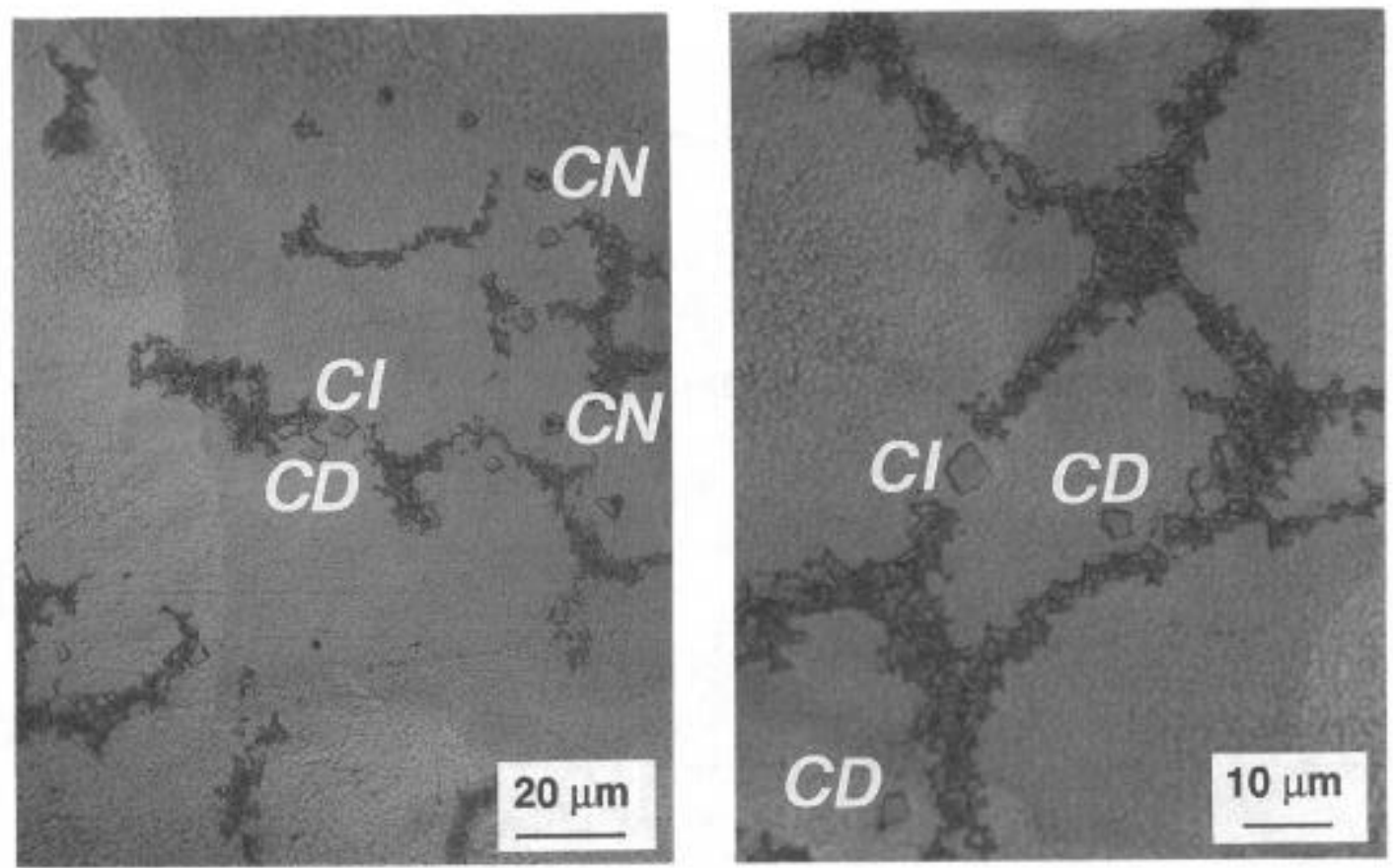

Figure 3(a)\&(b). Examples of carbides observed in a typical sample, (86A). The carbides are labelled and identified as $\mathrm{CN}$ for carbonitrides, $\mathrm{CD}$ for dendritic carbides (intradendritic), and $\mathrm{CI}$ for interdendritic carbides. Note that the $\mathrm{CD}$ carbides always appear close to the interdendritic regions. 


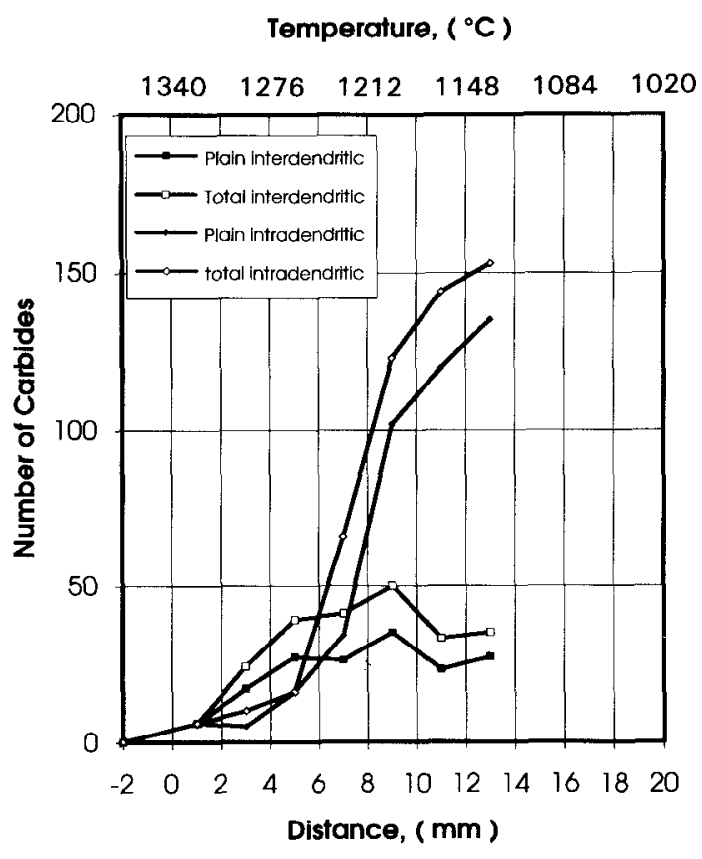

Figure 4. Sample 61A

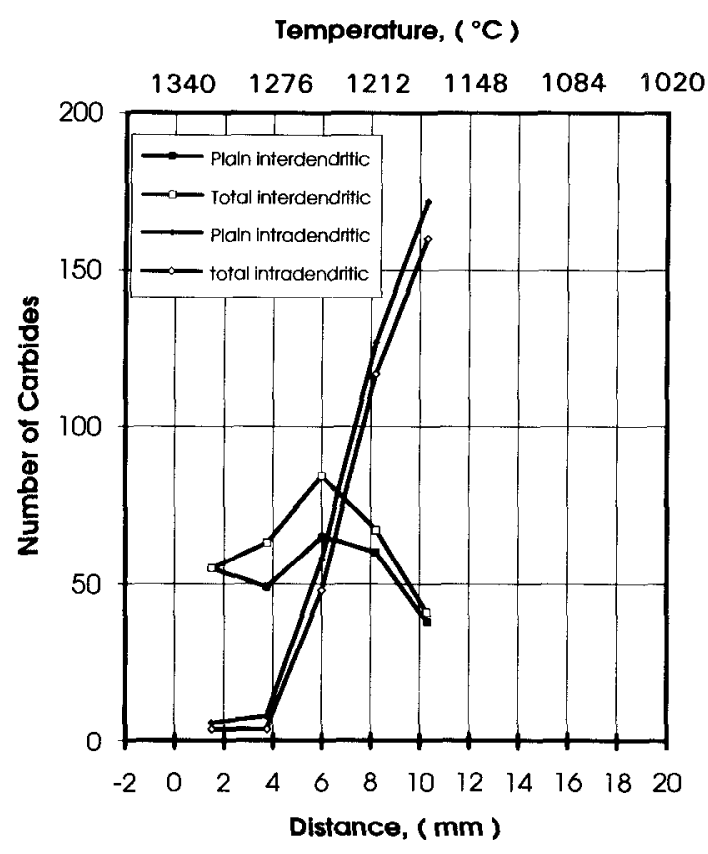

Figure 6. Sample 65B

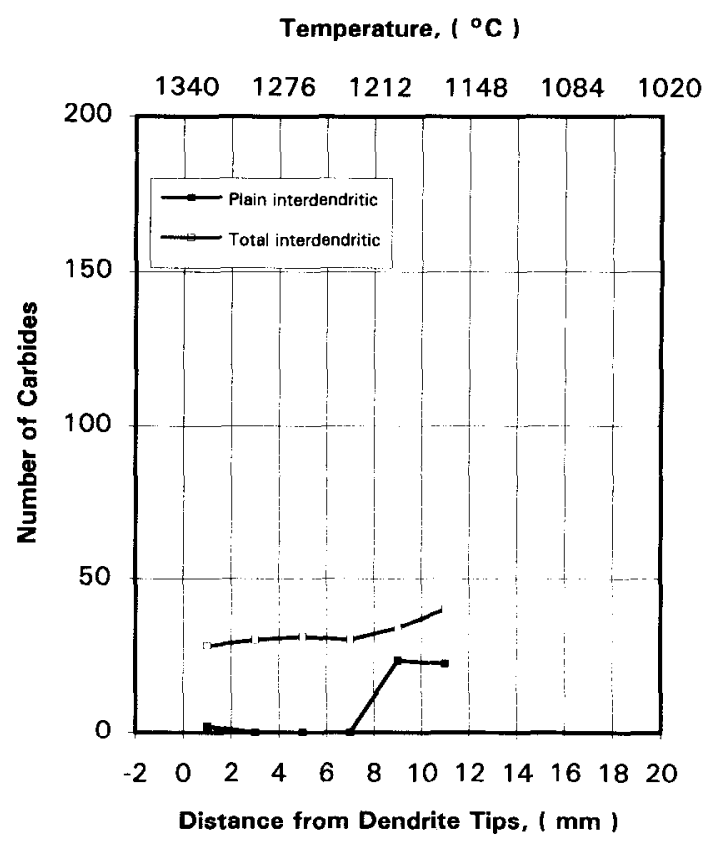

Figure 5. Sample 64

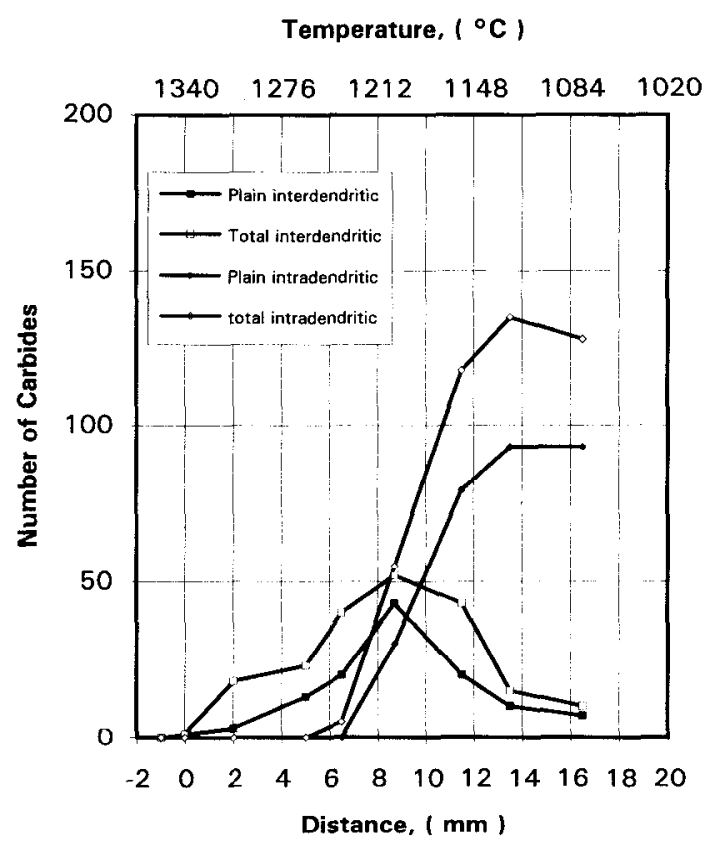

Figure 7. Sample 86

Figure 4-7. Number of carbides counted in DSQ samples in relation to the distance behind the growing dendrite tips of samples $61 \mathrm{~A}, 64,65 \mathrm{~B}$, and 86 respectively. The plain MC type carbide was distinguished from other variations of carbides such as carbonitrides and totalled. Location was distinguished as intradendritic (in dendrites) or interdendritic(between dendrites). 


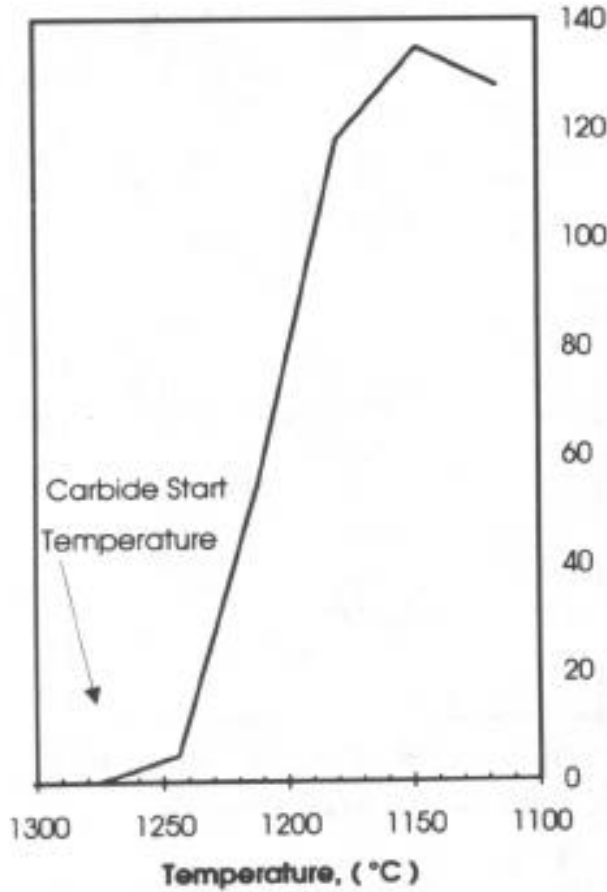

Figure 8. Carbide count in relation to temperature. The graph shows the carbide starting temperature to be extrapolated back to between $1250-55^{\circ} \mathrm{C}$.

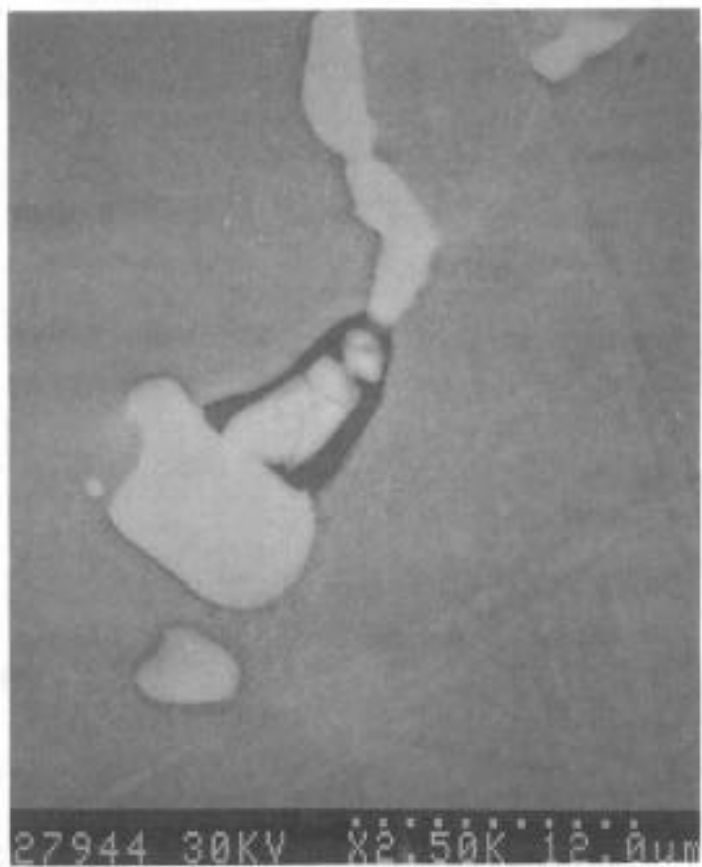

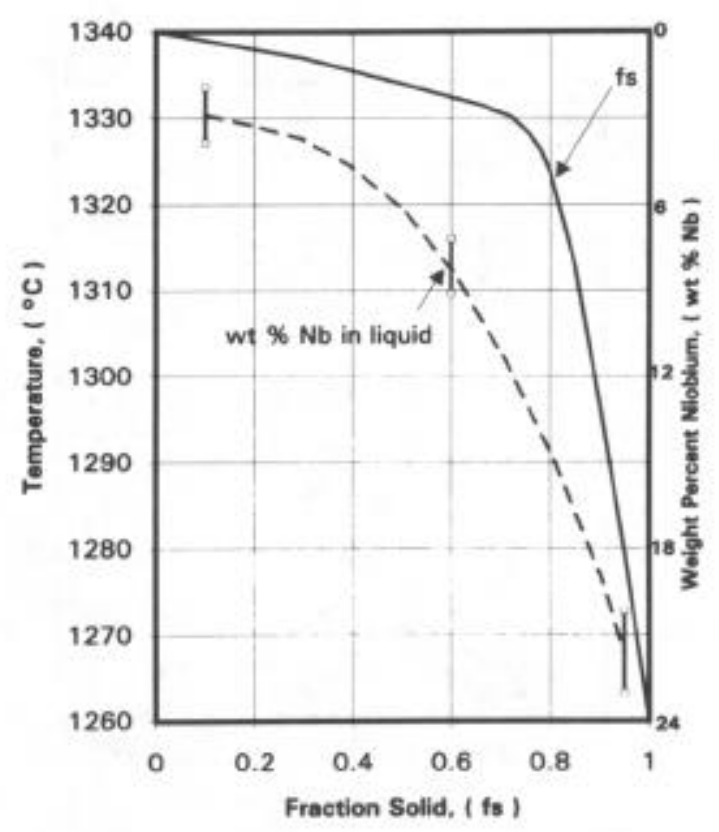

Figure 9. Weight $\% \mathrm{Nb}$ according to fraction solidified in relation to the temperature.

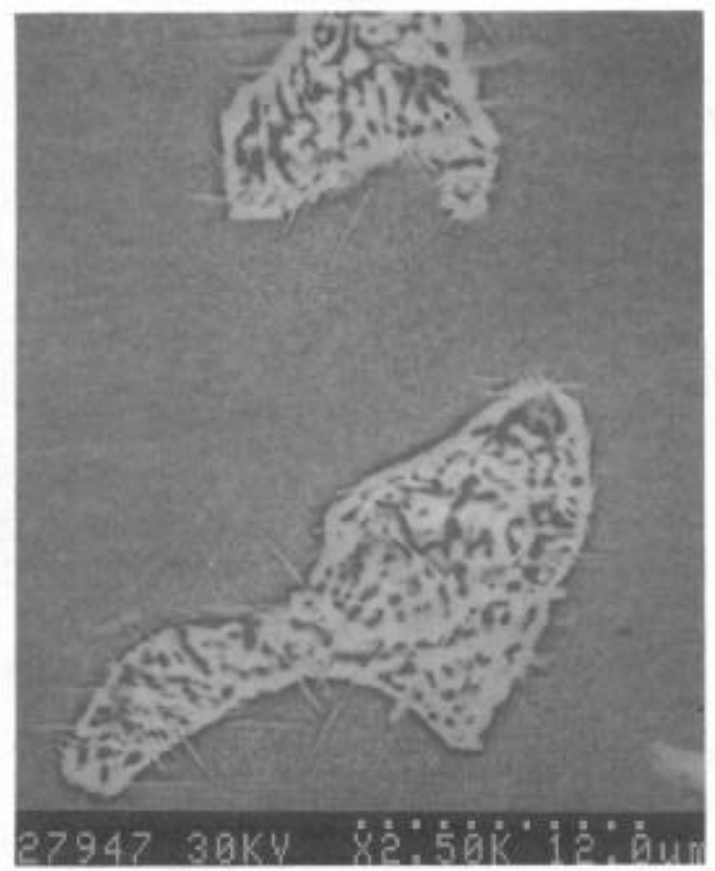

Figure 10(a)\&(b). Example of conventional Laves phase precipitation shown in 10(a). A distinctly different Laves phase region is shown in 10 (b) of EB processed material, of the same alloy composition other than $\mathrm{N}$ content. 

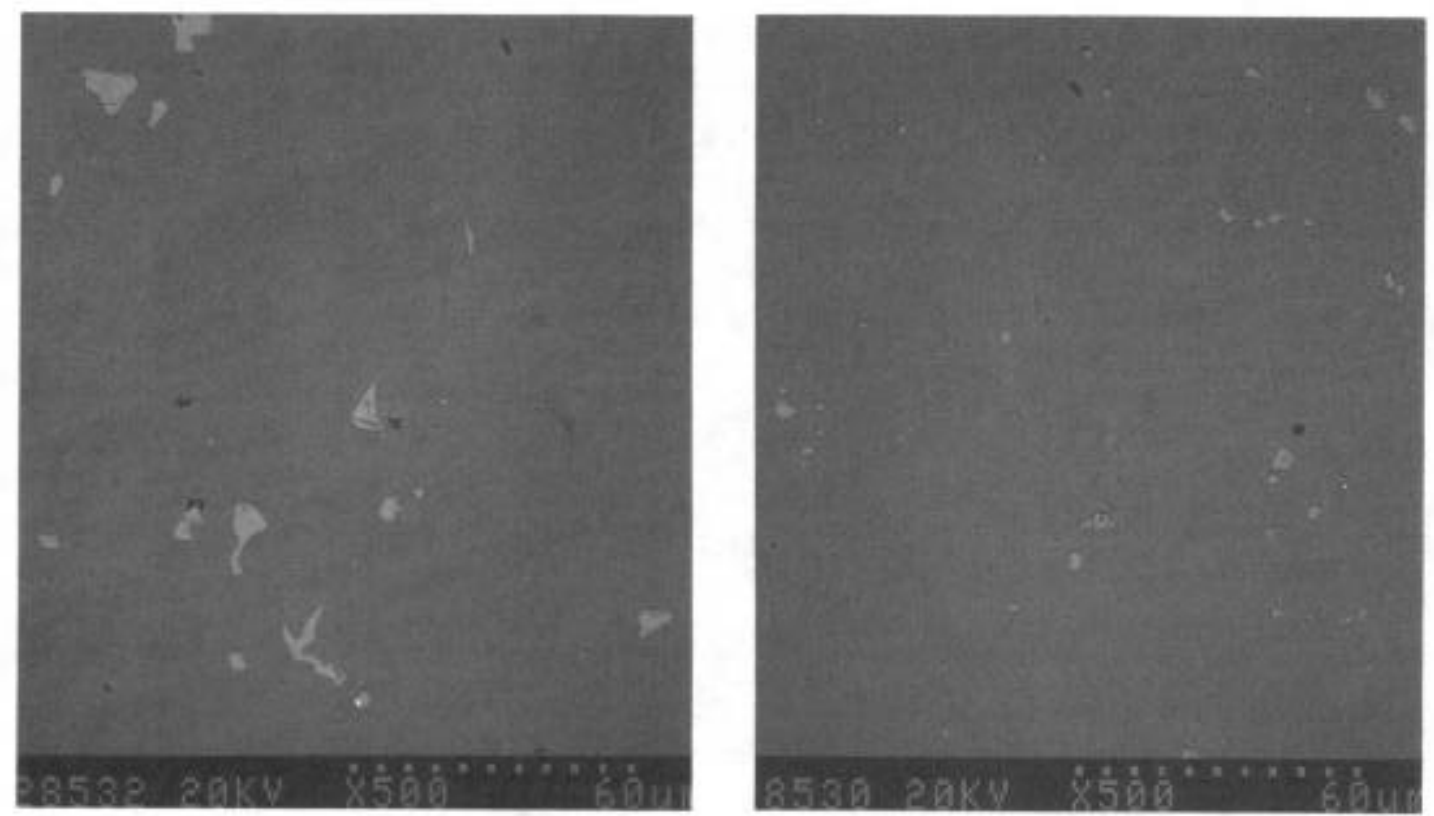

Figure 11(a)\&(b). Shows (a) conventionally melted and (b) EB remelted alloy homogenised at $1140^{\circ} \mathrm{C}$ for lhour. 11 (a) shows carbide and Laves phase, whereas, (b) shows only carbide precipitates.

\section{Appendix I}

Mass balance calculations are made for niobium and carbon distributed in the solidified samples based on the following conditions; the $\mathrm{Nb}$ and $\mathrm{C}$ appear (a) dendritically as solute and $\mathrm{NbC}$, (b) interdendritically as blocky $\mathrm{NbC}$ and $\gamma_{/} \mathrm{NbC}$, and (c) as $\mathrm{Nb}$ rich Laves phase. For calculation purposes the following assumptions are made: (1.) Niobium and carbon segregate at the solid-liquid interface following the Scheil equation; ( perfect mixing in the interdendritic liquid and no diffusion in the solid). (2.) Dendrites grow until a maximum niobium concentration is reached. (3.) The densities of liquid and solid are the same.

\section{Amount of Solute in the Dendrites}

From assumptions (1) and (2) it follows that the final fraction solid, $\mathrm{f}_{\mathrm{s}}$, of dendrites or $\gamma_{\text {phase }}$ is reached when the niobium concentration in the solid at the solid-liquid interface reaches the solubility limit. The amount of niobium and carbon in the dendrite in the solid fraction $\mathrm{f}_{\mathrm{S}}$ can then be calculated by integration of the Sheil Equation to give

$$
\mathrm{A} / \mathrm{X}_{\mathrm{O}}=1-\left(1-\mathrm{f}_{\mathrm{S}}\right)^{\mathrm{k}} \text {, }
$$

where $\mathrm{A}$ is the amount of solute per unit weight in the solid fraction or average concentration in the dendrites.

\section{Amount of Carbon as $\mathrm{NbC}$}

The amount of $\mathrm{C}$ as $\mathrm{NbC}$ can be calculated, ( Eq.(A3)), from the metallographic carbide counts assuming that the carbides are uniform in distribution and spherical in shape.

$$
\mathrm{CC}_{\mathrm{NbC}} / \mathrm{CC}_{\mathrm{o}}=\left(\mathrm{N}_{\mathrm{NbC}} / \mathrm{Vol} .\right) \cdot\left(4 / 3 \pi \mathrm{r}^{3}\right) \cdot\left(\mathrm{\rho}_{\mathrm{NbC}} / \rho_{718}\right) \cdot \mathrm{M}_{\mathrm{f}} \mathrm{C} / \mathrm{CC}_{\mathrm{O}}
$$

$$
\begin{aligned}
& \mathrm{CC}_{\mathrm{NbC}}=\text { Concentration of Carbon in } \mathrm{NbC} \rho_{\mathrm{NbC}}=\text { Density of Niobium Carbide } \\
& \mathrm{CC}_{\mathrm{O}}=\text { Nominal carbon concentration } \rho_{718}=\text { Density of Alloy } 718 \\
& \mathrm{~N}_{\mathrm{NbC}}=\text { Number of Carbides } \quad \mathrm{M}_{\mathrm{f}} \mathrm{C}=\text { Molar fraction of carbon in } \mathrm{NbC} \\
& \mathrm{r}^{=\text {Carbide radius } \quad \text { Vol. }=\text { Unit Volume }}
\end{aligned}
$$




\section{Carbon in $\gamma / \mathrm{NbC}$}

The amount of carbon in the eutectic can be calculated from a known volume fraction of eutectic. From ref. (1), $0.25 \%$ solidifies as a fine eutectic. Since it is assumed that the densities of liquid and solid are the same, thus the volume and weight fraction can also be considered to be the same. The fraction $\mathrm{NbC},\left(\mathrm{X}_{\mathrm{NbC}}\right)$, contained in the eutectic is calculated by solving the mass balance equations ( $\mathrm{Eq}$. A3) for $\mathrm{NbC}$ and $\gamma$. Taking the concentration of the eutectic as $19.1 \mathrm{wt} \% \mathrm{Nb}$, where $88.55 \mathrm{wt} \% \mathrm{Nb}$ is in $\mathrm{NbC}$, and $9.6 \mathrm{wt} \% \mathrm{Nb}$ in $\gamma$ ref. (1). The resulting balance becomes,

$$
19.1 \mathrm{wt} \% \mathrm{Nb}=(88.5 \mathrm{wt} \% \mathrm{Nb}) \mathrm{X}_{\mathrm{NbC}}+(9.6 \mathrm{wt} \% \mathrm{Nb}) \mathrm{X} \gamma
$$

giving, $\mathrm{X}_{\mathrm{NbC}}=0.12$. The fraction of $\mathrm{NbC}$ as eutectic in the sample is $0.25 \mathrm{f}_{\mathrm{L}} \mathrm{X}_{\mathrm{NbC}}$, when multiplied by the $\mathrm{M}_{\mathrm{f}} \mathrm{C}$ in $\mathrm{NbC}$ gives the weight fraction of Carbon in the sample forming the interdendritic eutectic;

$$
\mathrm{CC}_{\text {eutectic }}=0.25 \mathrm{f}_{\mathrm{L}} \mathrm{X}_{\mathrm{NbC}} \mathrm{M}_{\mathrm{f}} \mathrm{C}
$$

For example, equation (A4) is applied to data for a sample from ref. (1). Thus, taking $\mathrm{CNb}_{\mathrm{O}}$ $=5.25 \mathrm{wt} \%$, the Niobium solubility in $\gamma$ is $9.6 \mathrm{wt} \%$, the partition coefficient $\mathrm{k}$ is 0.5 . The fraction solid from the Sheil equation gives $\mathrm{f}_{\mathrm{S}}=0.9252$ or $\mathrm{f}_{\mathrm{L}}=0.0748$.

\section{Balance for Niobium}

The relative concentration of niobium is calculated to give $\mathrm{CNb}_{\mathrm{L}} / \mathrm{CNb}_{\mathrm{O}}=3.6571$ which gives $\mathrm{CNb}_{\mathrm{L}}=19.2 \mathrm{wt} \%$ for $\mathrm{CNb}_{\mathrm{o}}=5.25 \mathrm{wt} \%$. According to ref. (1), $25 \%$ of the interdendritic is eutectic $\gamma / \mathrm{NbC}$ and $75 \%$ is eutectic Laves with $19.1 \mathrm{wt} \%$ and $22.3 \mathrm{wt} \% \mathrm{Nb}$ respectively, giving an average interdendritic of $21.5 \mathrm{wt} \% \mathrm{Nb}$. The calculated concentration is $19.2 \mathrm{wt} \%$ representing a deficit of $2.3 \mathrm{wt} \% \mathrm{Nb}$ which is satisfactory given the experimental error and assumptions made.

a) Carbon in dendrites. The calculations are made for the same sample $0.04 \mathrm{wt} \% \mathrm{C}$. The density for liquid and solid alloy 718 is taken to be $8.2 \mathrm{~g} / \mathrm{cm}^{3}$. Using equation (A1) for niobium it was already obtained that $\mathrm{f}_{\mathrm{L}}=0.0748$. Using the same equations for carbon, the concentration of carbon in the dendrites as solute for a given $\mathrm{k}_{\mathrm{C}}$ is,

$\begin{array}{clll}\mathrm{k}_{\mathrm{C}} & 0.10 & 0.15 & 0.20 \\ \mathrm{C}_{\mathrm{Cs}} / \mathrm{C}_{\mathrm{Co}} & 0.228 & 0.322 & 0.405\end{array}$

b)Carbon as Carbides. Since there is no data on the number and size of blocky carbides in ref. (1), the carbon as $\mathrm{NbC}$ can be estimated as for sample 61 with $0.06 \mathrm{wt} \% \mathrm{C}$ and $5.67 \mathrm{wt} \%$ $\mathrm{Nb}$. A surface area scan of $0.22 \mathrm{~mm}^{2}$ gives 200 carbides with average size of $3.4 \mu \mathrm{m}$; giving a density of 27,410 carbides $/ \mathrm{mm}^{3}$. Taking $\rho_{\mathrm{NbC}}=7.6 \mathrm{~g} / \mathrm{cm}^{3}, \mathrm{M}_{\mathrm{f}} \mathrm{C}=0.114$, gives $\mathrm{CC}_{\mathrm{NbC}} / \mathrm{CC}_{\mathrm{O}}=0.12$ from Eq. (A2). This result indicates that $12 \%$ of the total carbon is present as blocky carbides, and was shown to be the case for most of the samples.

c) Carbon as Carbide in $\gamma / \mathrm{NbC}$ eutectic. Using Eq. (A3) where $\mathrm{f}_{\mathrm{L}}=0.0748, \mathrm{X}_{\mathrm{NbC}}=0.12$ and $\mathrm{M}_{\mathrm{f}} \mathrm{C}=0.114$ gives $\mathrm{CC}_{\text {eutectic }}=0.000256$ or $64 \%$ of the carbon. It is observed that for the present calculations a value of $\mathrm{kC}$ close to 0.1 closes the mass balance satisfactorily. 


\section{$\underline{\text { References }}$}

1. M.J.Ceislak, G.A.Knorovsky, T.J.Headley and A.D.Romig, Jr.; "The Solidification Metallurgy of Alloy 718 and Other Nb-containing Superalloys", "Superalloy 718" ed E.A.Loria, publ. TMS-AIME, warrendale, PA 1989, 59 - 69.

2. G.A.Knorovsky, M.J.Ceislak, T.J.Headley, A.D.Romig, Jr. and W.F.Hammetter;" Inconel 718; A Solidification Diagram"Metall. Trans. A, 20A (1989), 2147 - 2156.

3. B. Rhadakrishnan and R.G.Thompson; "Solidification of the Nickel-based Superalloy 718; A Phase Diagram Approach"; Metall. Trans. A, 20A (1989),2866 2868.

4. X. Xie, Y. Zhang, 7.. Xu, K. Ni, Y. Thu, T. Zhang, Y. Tong, X. Ning, S. Zhang and J.F. Radavitch; "Efeect of Oxygen, Nitrogren and Magnesium on Segregation, Solidification and Mechanical Properties in Alloy 718", "Superalloys 718 and 625", ed E.A.Loria, publ. TMS-AIME Warrendale PA, 1991, 241 - 251.

5. Personnel communication, Y Honnorat, 1992/ reported in"European Propulsion Forum 1993", Royal Aeronautical Soc., London UK.

6. A. Mitchell; "Recent Developments in Superalloy Melting Technology", "Synthesis, Processing and Modelling of Advanced Materials", eds. F.H.Froes and T. Khan, publ.Trans Tcch Publications, USA, 1991, 177 - 187.

7. A.S.Ballantync, A. Mitchell and J. F. Wadicr; "Prcdiction of Ingot Microstructure in VAR/ESR Alloy 718"; Proc. 6th International Conference on Vacuum Metallurgy, eds. G. K. Bhat and R. Schlatter, publ. American Vacuum Soc., New York, 1979, 599 $-623$.

8. G. K. Bouse; "Application of a Modified Phase Diagram to the Production of Cast Alloy 718 Components"; "Superalloy 718" ed E.A.Loria, publ. TMS-AIME Warrendale PA., 1989, 69 - 79.

9. M Hilborn; unpublished research, Univ. of Btirish Columbia, 1986.

10. U. Heubner, M. Kohler and B. Prinz; "Determination of the Solidification Behaviour of Some Selected Superalloys"; "Superalloys 1988", eds D.N.Duhl et al, publ. TMS-AIME Warrendale PA, 1988, 437 - 447.

11. J. M. Poole, Internal Report, INCO Alloys International, Huntington WVa, 1991.

12. W. L. Worrell and J. Chipman; "Carbide Equilibria at $1180-1370 \mathrm{~K}$ ", J. Phys. Chem. 68, (1964), $860-871$. 
13. S. L. Cockcroft, T. Degawa, A. Mitchell, D. W. Tripp and A. Schmalz; "Inclsion Precipitation in Superalloys", "Superalloys 92" eds S.D.Antolovich et al, publ. TMSAIME Warrendale PA, 1992, 577 - 589.

14 A. S. Ballantyne and A. Mitchell; "Prediction of Structure in VAR, ESR and PAR Ingots", "Solidification and Casting of Metals", Metals Society, London UK, 1979, $363-371$.

15. J.M.Moyer, "Extra-Low Carbon Alloy 718", "Proceedings of Superalloys 1984" eds. M. Gell et al, publ. TMS-AIME, Warrendale PA, 1984, 443 - 454.

16. K. O. Yu, J. A. Domingue, H. Flanders; "Segregation in VAR and ESR Alloy 718", Proceedings Vacuum Metallurgy Conference, Pittsburgh, eds. G.K.Bhat and L. H. Lherbier, publ. American Vacuum Soc, New York, 1985, 1 - 8. 